\title{
Tablas Nacionales de Crecimiento: peso y talla puestos a prueba
}

\section{Objetivo}

Establecer la vigencia de los estándares nacionales (ENV) de peso y talla comparándolos con una muestra nacional actualizada de niños representada en el Programa Nacional Colaborativo (PNC).

\section{Diseño}

Corte Transversal ${ }^{*}$

Se compararon las muestras con las que realizaron los ENV (niños medidos en el periodo 1966 - 1975) con la muestra del PNC, obtenida en el periodo 1991-1992. Los datos de los ENV provinieron de 3 muestras:

-Un estudio longitudinal de niños sanos seguidos por 3 años, La Plata, 1966.

-Dos muestras de corte transversal, de niños residentes en zona urbana de la ciudad de la Plata y Córdoba. 1974-1975.

La muestra del PNC, corte transversal, incluye niños sanos entre 0 y 6 años, evaluados desde agosto 1991 hasta diciembre 1992 por 129 pediatras, en consultorio público o privado, seleccionados al azar. La distribución geográfica fue representativa de todo el país. Se calcularon los percentilos 50 (PC 50) de peso y altura a edades específicas y los desvíos estándares en cada intervalo etario. Se compararon los PC50 de la muestra del PNC y la muestra de los ENV.

\section{Lugar}

Argentina. Servicio de Crecimiento y Desarrollo Hospital Nacional de Pediatría"Prof. Juan P. Garraham"

\section{Pacientes}

Dos grupos:

1.Pacientes de los ENV:

a. 250 niños, de 0 a 3 años, de clase media y media baja asistidos en un consultorio externo hospitalario. Finalizaron el estudio 116 niños.

b.Dos muestras transversales de 4 a 12 años, 3600 niños. Residentes de área urbana de la ciudad de la Plata y Córdoba.
2.Pacientes del PNC: 3573 niños sanos (1775 niñas, 1797 niños), de 0 a 6 años, Criterios de inclusión: ausencia de enfermedad crónica, peso al nacimiento mayor de 2.500 gramos, residencia familiar mayor a un año en la localidad donde el niño fue evaluado.

\section{Resultados Principales}

La talla de los niños en los primeros 3 años de edad fue menor en la muestra actual que en los estándares nacionales. Luego de esta edad presenta una tendencia de mediciones mayores que los estándares.

En las niñas los pesos de los datos actuales son mayores que los de los estándares durante los 2 primeros años, y son menores o similares a edades mayores (máxima diferencia: 650 grs a los 6 meses). Los niños, presentaron pocas diferencias y de escasa magnitud durante los primeros 2 años, luego se observaron pesos mayores que los estándares, siendo la máxima diferencia de 600 grs a los 4 años.

Tabla. Comparación de estándares nacionales (ENV) y datos actuales (PNC): peso y talla, niños y niñas

\begin{tabular}{|c|c|c|c|c|c|c|c|c|}
\hline Edad & \multicolumn{3}{|c|}{ Estándares Nacionales(ENV) } & \multicolumn{3}{|c|}{ Datos Actuales(PNC) } & \multicolumn{2}{|c|}{ Diferencia PNC-ENV } \\
\hline Niñas & N & Peso(PC50) & Talla(PC50) & N & Peso(PC50) & Talla(PC50) & Peso(Kg.) & Talla(cm.) \\
\hline $3 m$ & 120 & 5,30 & 59,10 & 115 & 5,75 & 59,06 & $+0,45$ & $-0,04^{*}$ \\
\hline 4 a & 142 & 16,25 & 99,70 & 302 & 16,10 & 101,34 & $-0,15$ & $+1,64^{*}$ \\
\hline 5 a & 136 & 17,90 & 106,70 & 309 & 18,00 & 107,86 & $+0,10$ & $+1,16^{*}$ \\
\hline Niños & & & & & & & & \\
\hline $3 \mathrm{~m}$ & 129 & 6,00 & 62,30 & 102 & 6,10 & 60,07 & $+0,10$ & $-2,23^{*}$ \\
\hline $4 a$ & 137 & 16,40 & 101,20 & 279 & 17,00 & 102,22 & $+0,60$ & $+1,02^{*}$ \\
\hline 5 & 143 & 18,60 & 108,00 & 304 & & 109,26 & 0,40 & \\
\hline
\end{tabular}

*Diferencias no significativas

\section{Conclusión}

Este trabajo demuestra que los estándares en niños entre 0 y 6 años siguen vigentes. Las diferencias encontradas no son sistemáticas, y las halladas fueron de escasa magnitud.

Fuente de financiamiento: sin apoyo económico externo.

\section{Comentario}

En la práctica ambulatoria, el control del niño sano ocupa un lugar de primordial importancia. Evaluar el estado de salud de los niños, aporta datos para realizar tareas preventivas, permitiendo realizar intervenciones de alto impacto.

La actividad central del control del niño sano es la evaluación del crecimiento y desarrollo. Algunos parámetros usados habitualmente en la práctica para evaluar crecimiento son la medición de talla, peso, perímetro cefálico, velocidad de crecimiento, relación peso/talla. Las tablas vigentes para esta actividad, son las publicadas por el Comité de Crecimiento y Desarrollo de la Sociedad Argentina de Pediatría en 1987. Estas incluyen niños de 0 a 19 años, realizadas con datos recolectados, principalmente, hace mas de 35 años, en La Plata y Córdoba', pertenecientes a una clase social no representativa de todo el país.
Entendiendo que las características poblacionales han cambiado, la actual muestra ${ }^{2}$ actualiza y contrapone, de manera más consistente y representativa, los datos a los ya existentes, asegurando la vigencia de los estándares nacionales para peso y talla, en los niños y niñas de 0 a 6 años. No podemos asegurar lo mismo en niños mayores o en relación a otros parámetros de crecimiento.

\section{Conclusiones del comentador}

Los estándares nacionales de crecimiento siguen vigentes claramente hasta los 6 años, más allá de esta edad debemos procurar la realización de estudios que demuestren esta continuidad.

Dra. Sandra Fraifer. [ Coordinadora Residencia Medicina Familiar. OSPeCon.Construir Salud ] 